\title{
Rancang Bangun Alat Pelipat Baju Sebagai Media Pembelajaran Bagi Anak-Anak Via Smartphone
}

\author{
Ilham Saputra ${ }^{1}$, Emil Nafan $^{2}$, Retno Devita $^{3}$, Nurhadi $^{4}$ \\ ${ }^{1)}$ Program Studi Sistem Komputer, Universitas Putra "YPTK" Padang \\ 2) Program Studi Teknik Informatika, STMIK Dumai \\ Jl. Raya Lubuk Begalung Padang - Sumatera Barat, Indonesia \\ Jl. Utama Karya No. 04 Bukit Batrem - Dumai, Indonesia \\ Email: emilnafan@upiyptk.ac.id
}

\begin{abstract}
ABSTRAK
Pekerjaan rumah tangga adalah salah satu kegiatan yang banyak menyita waktu. Tidak hanya itu, kegiatan ini dilakukan setiap hari, dan tentunya ketika ada pekerjaan rumah yang terbengkalai tidak akan merasa nyaman untuk ditinggalkan. Diantara salah satu pekerjaan rumah tangga yang menjadi perhatian untuk masalah ini adalah dalam hal melipat baju hasil pengeringan. Anak-anak sejak dini harus ditanamkan rasa mandiri agar tidak menjadi manja dikemudian hari, diantaranya mengajarkan cara melipat baju kepada anak-anak tentunya akan membuat waktu terbuang karena masih banyak aktivitas lain yang harus dilakukan.Dari permasalahan tersebut, penulis ingin membuat sebuah alat dimana alat ini bekerja dengan Arduino Mega 2560 sebagai pengontrol dan bahasa C sebagai bahasa pemrogramannya. Menggunakan motor servo sebagai penggerak alat untuk melipat baju di sisi kiri, kanan, dan bawah. Modul Bluetooth HC-05 sebagai koneksi antara alat dengan smartphone. LCD Grafik digunakan sebagai output untuk menampilkan informasi. Dari hasil pengujian yang telah dilakukan sistem yang dirancang dapat bekerja dengan baik dan bisa digunakan sebagai media pembelajaran bagi anak-anak dalam proses kegiatan melipat baju.
\end{abstract}

Kata kunci: Modul Bluetooth HC-05, Android, Motor Servo sebagai penggerak.

\begin{abstract}
Housework is one of the most time-consuming activities. Not only that, this activity is carried out every day, and of course when there is neglected homework you will not feel comfortable to be left behind. One of the household chores that is a concern for this problem is folding dried clothes. Children from an early age must be instilled a sense of independence so as not to be spoiled in the future, including teaching how to fold clothes to children, of course it will waste time because there are still many other activities that must be done. From these problems, the author wants to make a tool where the tool it works with Arduino Mega 2560 as controller and $C$ language as programming language. Using a servo motor as a driving tool to fold clothes on the left, right, and bottom. HC-05 Bluetooth Module as a connection between the device and the smartphone. Graphic LCD is used as output to display information. From the results of the tests that have been carried out, a system designed to work well and can be used as a learning medium for children in the process of folding clothes.
\end{abstract}

Keywords: Bluetooth Module HC-05, Android, Servo Motor as a driver. 


\section{Pendahuluan}

Perkembangan ilmu pengetahuan dan teknologi saat ini sangatlah pesat, dan berperan mewujudkan kehidupan yang lebih baik. Teknologi elektronika menjadi salah satu bagian dalam membantu meringankan pekerjaan manusia, telah diciptakan berbagai alat elektronika yang praktis dan efisien untuk membantu manusia dalam memenuhi kebutuhannya. Dewasa ini berbagai macam peralatan yang sistem pengoperasiannya secara manual semakin ditinggalkan dan beralih pada peralatan serba otomatis, sehingga peralatan otomatis lebih mendominasi kehidupan manusia.Di zaman modern pada saat sekarang ini melihat banyak sekali anak-anak yang sudah menggunakan gadget terutama smartphone dan mereka juga sangat pandai memakainya, tidak hanya itu kadang waktu mereka habis karena memainkan smartphone mereka terutama bermain game mobile yang pada sekarang ini sedang marak-maraknya, pulang sekolah yang mereka cari terlebih dahulu adalah smartphone bukan buku pelajaran mereka sibuk sendiri menatap layar smartphone mereka sepanjang hari sehingga melupakan aktivitas-aktivitas mereka yang lain.Pekerjaan rumah tangga adalah salah satu kegiatan yang banyak menyita waktu. Tidak hanya itu, kegiatan ini dilakukan setiap hari, dan tentunya ketika ada pekerjaan rumah yang terbengkalai tidak akan merasa nyaman untuk ditinggalkan. Diantara salah satu pekerjaan rumah tangga yang menjadi perhatian untuk masalah ini adalah dalam hal melipat baju hasil pengeringan. Anak-anak sejak dini harus ditanamkan rasa mandiri agar tidak menjadi manja dikemudian hari, diantaranya mengajarkan cara melipat baju kepada anak-anak tentunya akan membuat waktu terbuang karena masih banyak aktivitas lain yang harus dilakukan. Untuk mewujudkan hal tersebut diperlukan suatu alat yang mampu melipat baju sekaligus berfungsi sebagai media pembelajaran bagi anak-anak melalui smartphone. Penelitian tentang pelipat baju otomatis ini sudah banyak dilakukan oleh peneliti sebelumnya, namun kebanyakan input pengendalian alat berasal dari penekanan tombol (push button). Belum ditemukan sistem pelipat baju yang menggunakan input dari smartphone. Dengan menggunakan peralatan yang dikendalikan melalui handphone diharapkan lebih menarik minat anak-anak dalam melakukan kegiatan melipat baju. Dengan demikian waktu mereka bisa menjadi lebih bermanfaat.

\section{Metode Penelitian}

Adapun metode penelitian yang dilakukan sebagai adalah berikut:

a. Penelitian Alat Pada penelitian alat ini dilakukan pemilihan alat yang terkait sesuai dengan alat yang dibuat serta mengetahui bagaimana masyarakat bisa mengerti dalam penggunaan alat yang akan digunakan dan memudahkan petugas kebersihan dalam menangani sampah.

b. Riset Perpustakaan Riset perpustakaan ini dilakukan dengan cara membaca, membahas, meringkas dan membuat kesimpulan dari buku-buku dan jurnal tentang komponen apa saja yang digunakan pada alat dan programing yang berkaitan dengan analisa dan perancangan alat yang dibuat dengan algoritma pemrograman Arduino untuk mendapatkan bahan-bahan yang secara ilmiah dapat dijadikan landasan dalam menyusun penelitian ini. 


\section{Hasil dan Pembahasan}

\section{Context Diagram}

Context diagram berfungsi sebagai media, yang terdiri dari suatu proses dan beberapa external entity. Context diagram yang dimaksud dapat dilihat pada gambar 1 berikut ini:

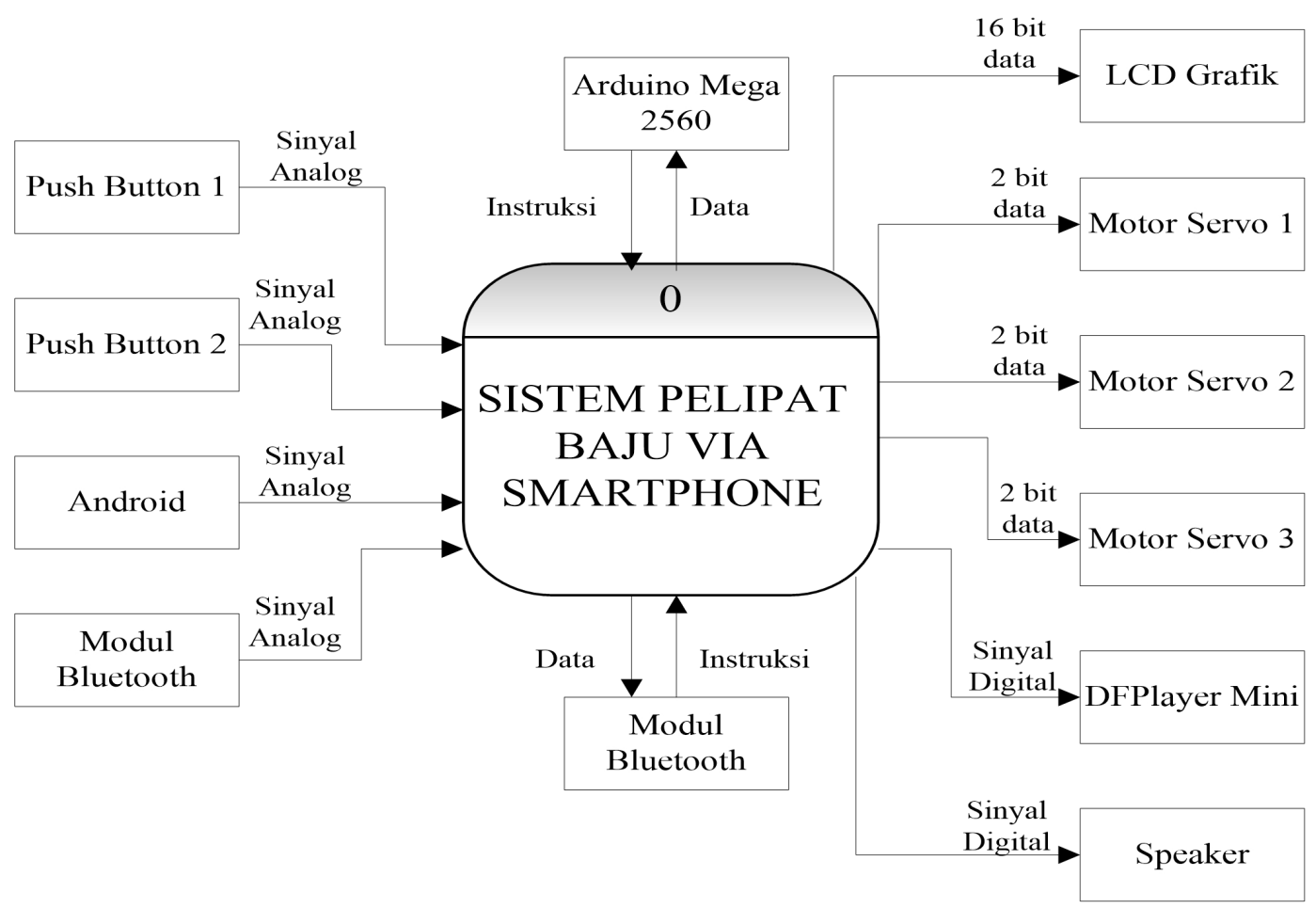

Gambar 1. Context Diagram

Sesuai dengan penamaannya maka proses ini akan mengolah data input menjadi output.

Proses ini akan berinteraksi dengan beberapa entity yaitu :

1. Arduino Mega 2560 berfungsi sebagai pengontrol dari semua sistem pada semua komponen agar alat bekerja dengan baik.

2. Smartphone berfungsi sebagai kendali untuk menjalankan alat pelipat baju.

3. Modul Bluetooth berfungsi sebagai pengkoneksian antara alat dengan smartphone.

4. Push Button 1 juga berfungsi sebagai tombol untuk menjalankan alat pelipat baju jika smartphone dalam keadaan mati atau koneksi antar alat dengan smartphone terputus.

5. Push Button 2 berfungsi untuk tombol reset agar alat kembali dalam keadaan semula.

6. Modul program berfungsi sebagai intruksi untuk menerima data dari pengkoneksian antara alat dengan smartphone melalui modul Bluetooth, smartphone dan push button 1 sebagai input untuk menjalankan alat lalu push button 2 untuk reset dan menghasilkan output berupa motor servo 1, 2 dan 3 serta aktifasi terhadap LCD Grafik dan juga speaker.

7. LCD Grafik berfungsi sebagai media tampilan dari alat pelipat baju.

8. Motor servo 1, 2 dan 3 berfungsi sebagai penggerak untuk melipat setiap bagian dari baju. 
9. DFPlayer berfungsi sebagai pengaktifasian intruksi dari modul program kepada speaker.

10. Speaker berfungsi sebagai keluaran informasi dari alat pelipat baju.

\section{Rangkaian Arduino Mega 2560}

Arduino Mega 2560-R3 merupakan board mikrokontroler berbasis Atmega 2560. Arduino Mega 2560-R3 memiliki 54 pin I/O digital dimana 15 pin diantaranya dapat digunakan sebagai output Pulse Width Modulation (PWM), 16 input analog, 4 UARTs (port serial perangkat keras), osilator kristal $16 \mathrm{MHz}$, koneksi USB, tombol reset, power jack, dan ICSP header. Sebagai pendukung agar mikrokontroler dapat digunakan, Arduino Mega 2560 dapat dihubungkan dengan menggunakan kabel USB ke komputer atau dengan memberi catu daya dengan adaptor AC ke DC atau menggunakan baterai. Selain itu, Arduino Mega 2560-R3 juga cocok untuk menggunakan shield yang di desain untuk Arduino jenis sebelumnya.

\section{Rangkaian LCD Grafik}

LCD atau Liquid Crystal Display adalah suatu jenis media display (tampilan) yang menggunakan kristal cair (liquid crystal) untuk menghasilkan gambar yang terlihat. Teknologi Liquid Crystal Display (LCD) atau penampil kristal cair sudah banyak digunakan pada produk-produk seperti layar laptop, layar ponsel, layar kalkulator, layar jam digital, layar multimeter, monitor komputer, televisi, layar game portabel, layar termometer digital dan produk-produk elektronik lainnya.

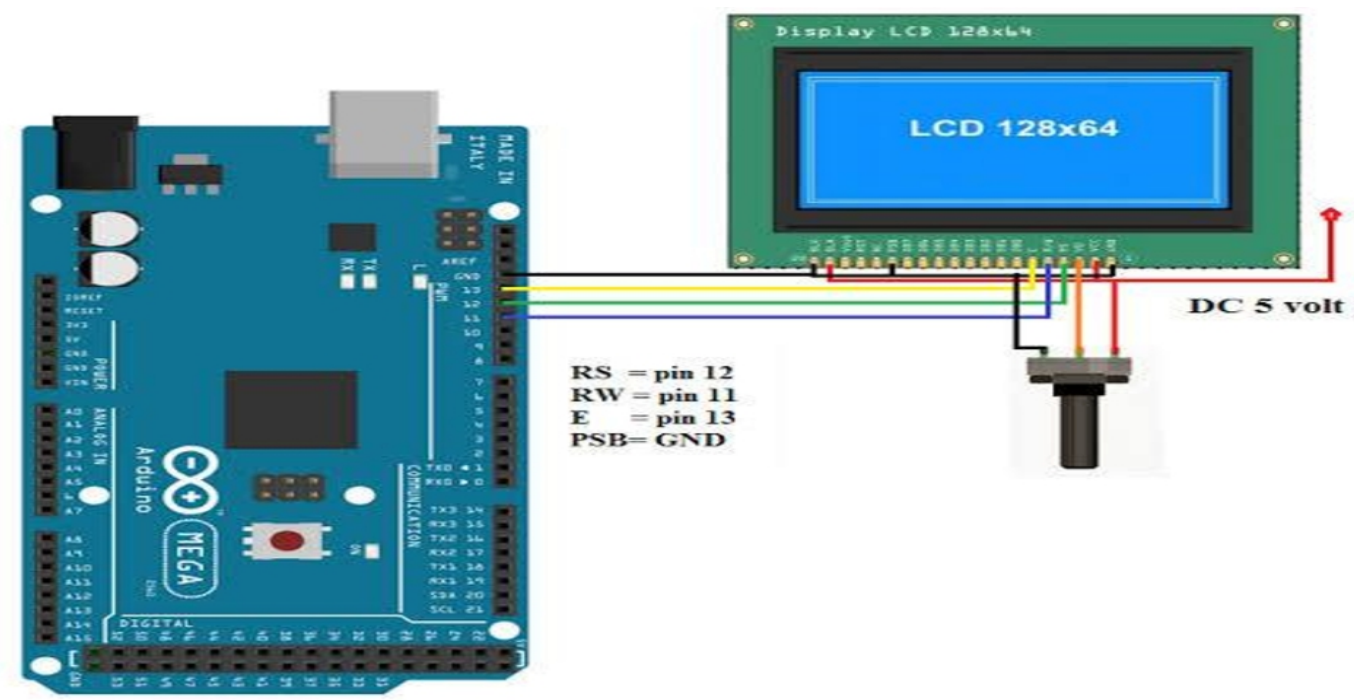

Gambar 2. Rangkaian LCD Grafik

Pada gambar rangkaian di atas dapat dilihat susunan pin pada LCD Grafik yaitu sebagai berikut :

1. Pin VSS ke GND Arduino Mega 2560

2. Pin VDD ke VCC Arduino Mega 2560

3. Pin V0 ke pin Potensio 
4. Pin D ke pin 23 Arduino Mega 2560

5. Pin R ke 25 Arduino Mega 2560

6. Pin E ke pin 27 Arduino Mega 2560

\section{Rangkaian Modul Bluetooth}

Push button adalah tipe skalar yang hanya kontak sesaat saja saat ditekan dan telah dilepas maka akan kembali lagi menjadi Normally Open (ON), biasanya saklar tipe on ini memiliki rangkaian penguncinya yang dihubungkan dengan konektor dan tipe on digunakan untuk tombol on. Push button ada juga yang bertipe Normally Close (NC), biasanya digunakan untuk tombol off.

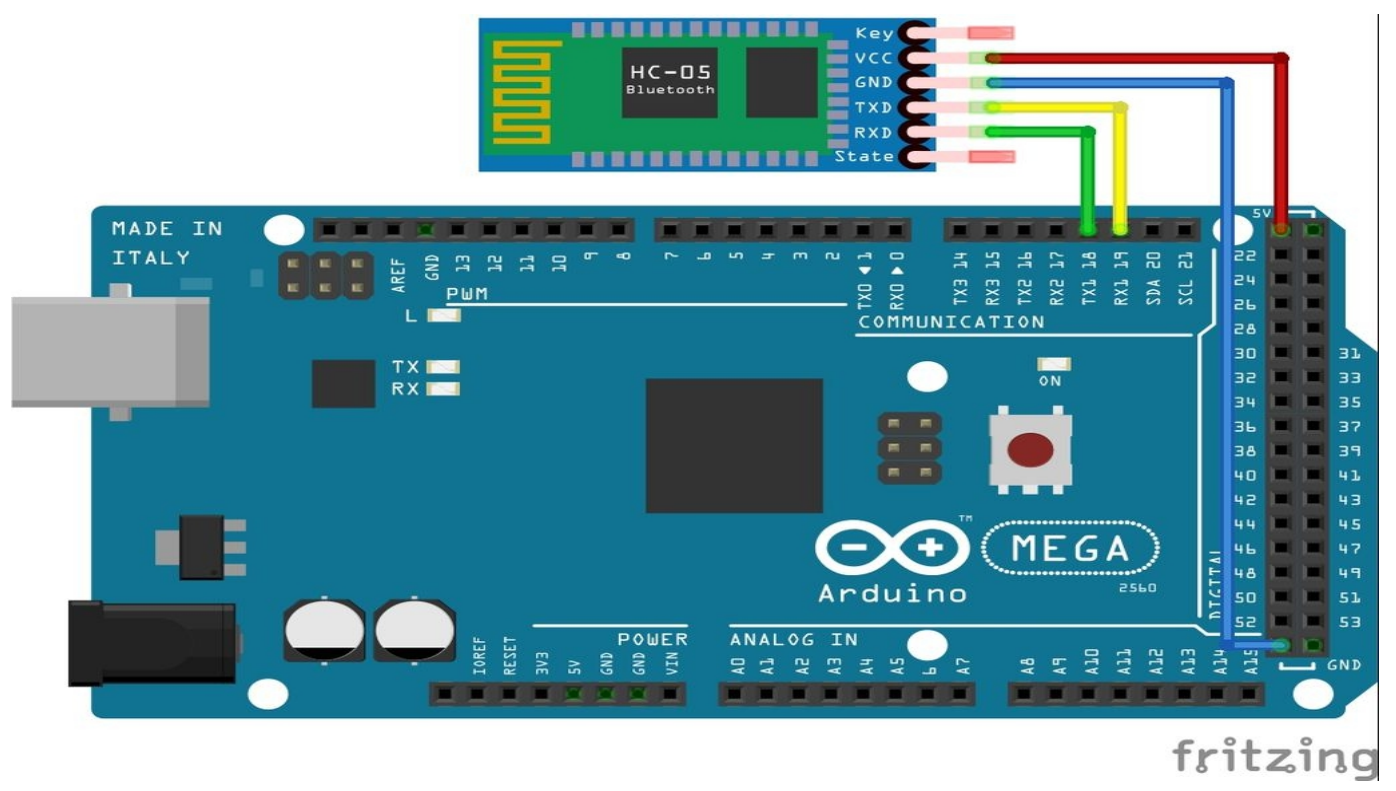

Gambar 3. Rangkaian Modul Bluetooth

Pada gambar rangkaian di atas dapat dilihat susunan pin pada push button yaitu sebagai berikut :

1. Pin RXD Modul Bluetooth ke pin 18 Arduino

2. Pin TXD Modul Bluetooth ke pin 19 Arduino

3. Pin GND Modul Bluetooth ke pin GND Arduino

4. Pin VCC Modul Bluetooth ke pin VCC Arduino

\section{Rangkaian DFPlayer Mini}

DFPlayer Mini adalah modul mp3 yang lansung dapat dihubungkan ke speaker. Modul ini digunakan secara standalone (daya dari baterai) dengan menggunakan beberapa push button dan speaker atau dikombinasikan dengan Arduino. 

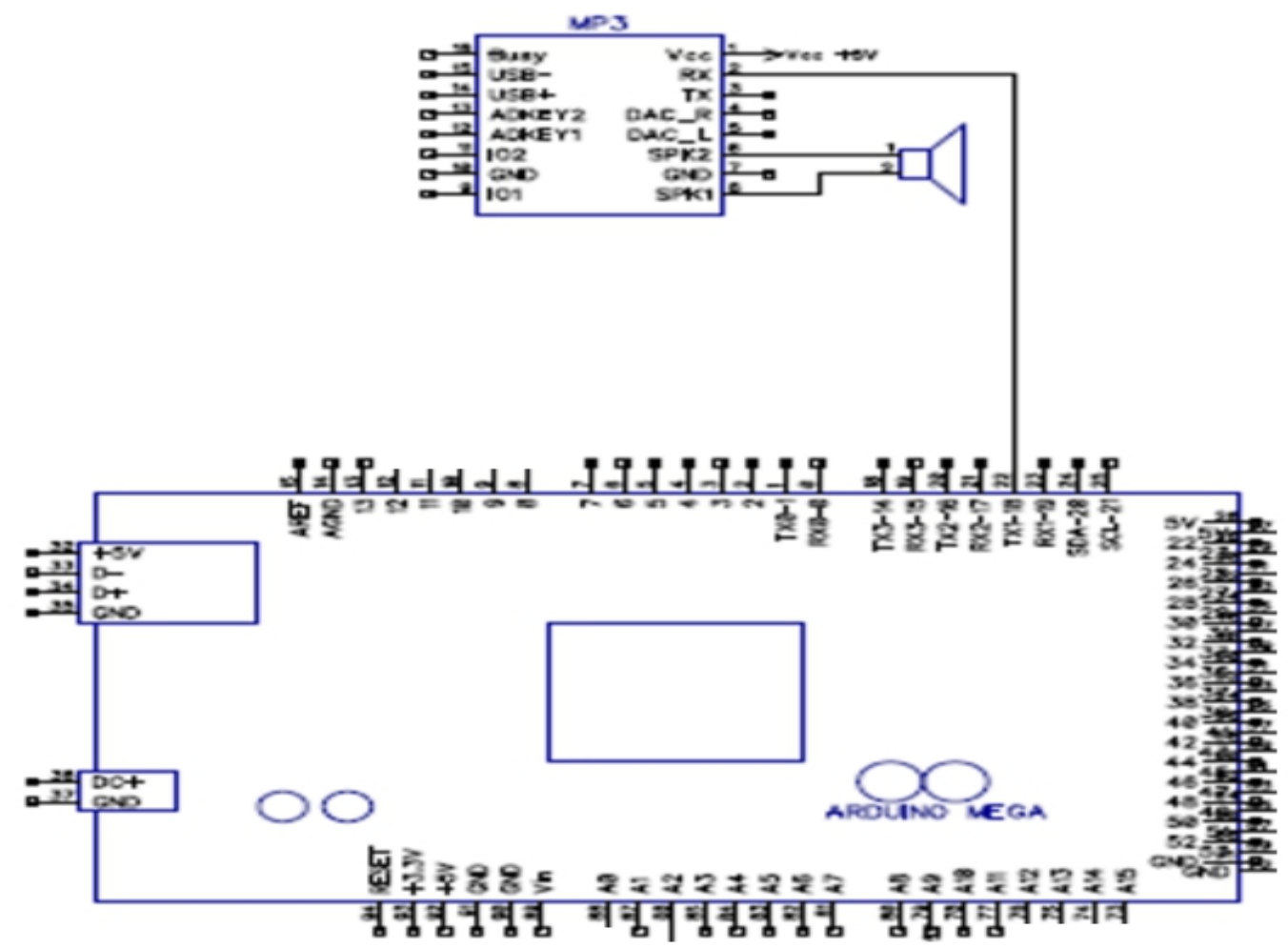

Gambar 4. Rangkaian DFPlayer Mini

Pada gambar rangkaian di atas dapat dilihat susunan pin pada DFPlayer Mini yaitu sebagai berikut :

1. Pin 2 DFPlayer Mini ke pin 22 Arduino

2. Pin 6, 8 DFPlayer Mini ke pin 1, 2 Speaker

\section{Pengujian Sistem}

Untuk kendali sistem secara keseluruhan, kendalinya dipegang sepenuhnya oleh Arduino Mega 2560 berdasarkan program yang tersimpan dalam modul program. Untuk pengujian dari sistem ini dapat dilakukan dengan langkah langkah sebagai berikut:

1. Sistem diawali dengan Tombol untuk memulai dari sistem kerja alat.

2. Tampilan awal dari alat pelipat baju otomatis dapat dilihat pada LCD Grafik untuk menampilkan informasi berupa perintah meletakkan baju.

3. Motor Servo berfungsi untuk menggerakkan alat pelipat baju otomatis.

4. Alat pelipat baju otomatis akan melipat baju yang telah diletakkan di alat.

5. LCD Grafik akan menampilkan informasi pada saat melipat baju.

6. Apabila semua proses telah selesai maka akan tampil informasi di LCD Grafik bahwa proses sudah selesai.

7. Jika ingin menghidupkan alat menggunakan android, maka berikut tampilan pada android.

8. Modul bluetooth digunakan sebagai koneksi antara alat dengan android. 


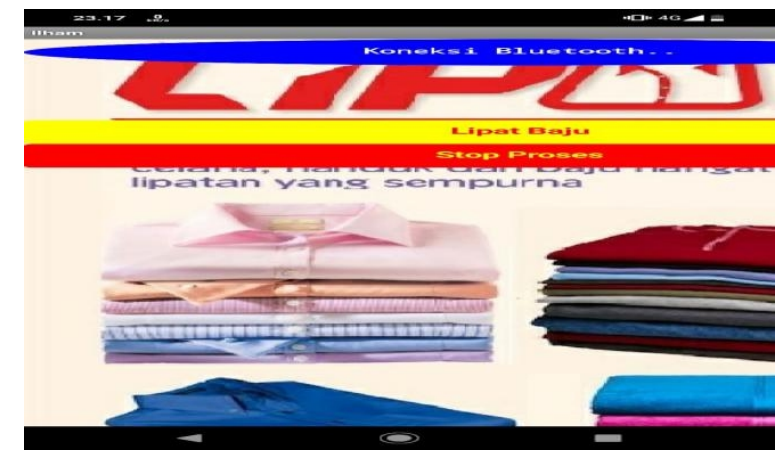

Gambar 5. Tampilan Aplikasi Android

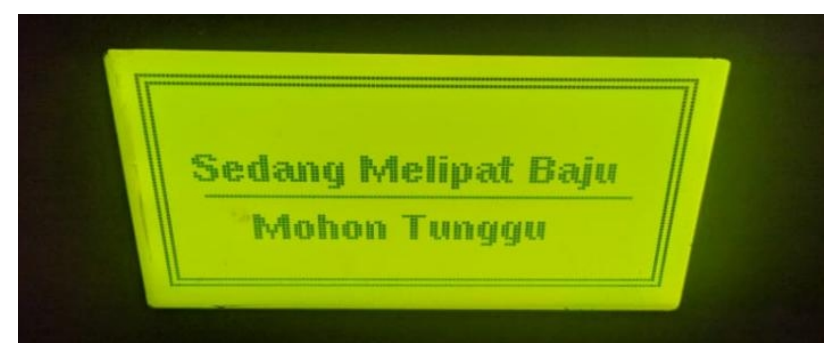

Gambar 6. Tampilan LCD Grafik saat melipat baju

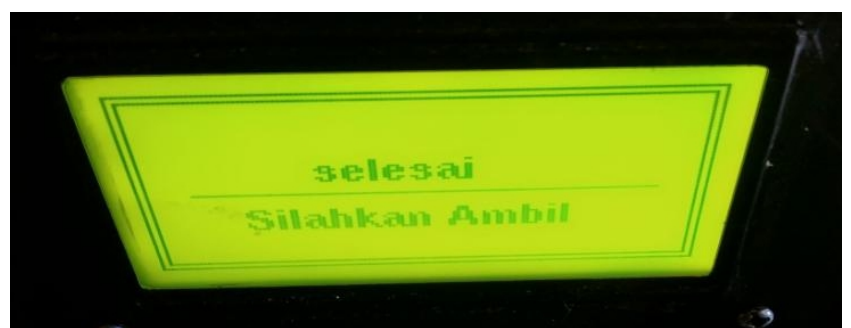

Gambar 7. Tampilan LCD Grafik pada saat proses telah selesai

\section{Simpulan}

Alat pelipat baju mampu bekerja dengan baik sehingga mampu membantu user dalam melipat baju dengan menggunakan smartphone sebagai pengendalinya. Motor Servo dapat bekerja melipat bagian-bagian baju dengan baik. LCD disini untuk menampilkan informasi dalam pada alat pelipat baju. Modul Bluetooth dapat mengkoneksikan alat pelipat baju dengan smartphone. Speaker bisa menampilkan informasi dengan baik pada alat pelipat baju. Dalam melakukan perancangan dan pembuatan alat pembuat es kepal milo otomatis tersebut masih terdapat keterbatasan sistem yang meliputi: Alat pelipat baju masih bisa dikatakan belum sempurna karena alat tersebut hanya bisa melipat baju yang berlengan pendek saja. Sehingga dalam perancangan mekanik pada alat tersebut perlu dilakukan pengembangan dan penyempurnaan untuk mendapatkan hasil yang baik dan benar menjadi penemuan yang berguna dan tepat sasaran meski perkembangan alat masih dapat direnovasi. 


\section{Daftar Pustaka}

Andrianto, Heri, Aan, Darmawan. (2016). Arduino Belajar Cepat dan Pemograman. Bandung: Informatika.

Abim Nurcahyo, S M. Ibrahim, (2019). Ashari Sotyohadi Alat Pelipat Pakaian Otomatis Berbasis Pengendali Mikro. Seminar Hasil Elektro S1 ITN Malang.

Afdillah, Wahyu. Sari, Febrina. Satria, Devit., (2018). Prototype Robot Lengan Pemindah Barang dengan Kendali Lengan Manusia Berbasis Arduino Uno. Sekolah Tinggi Teknologi Dumai.

Basuki Rahmat, (2019). Rancang Bangun Alat Pelipat Baju Menggunakan Pegassebagai Mekanisme Penggerak Manual. Universitas Islam Indonesia. Tugas Akhir.

Cekdin, Cekmas. (2017). Sistem Teknik Kendali. Yogyakarta: Andi.

Darmawan, Deni. (2015). Sistem Informasi Manajemen. Bandung: Remaja Rosdakarya.

Erwin Sukma Bukardi, Wahyu Setyo Pambudi. (2015). Perancangan Dan Pembuatan Semi Automatic T-Shirt Foldingmachine Menggunakan Metode Fuzzy Proportional Derivative(Fpd). Jurn Jurnal Sains dan Teknologi. Vol. 1,No. 1, Juni 2015.

Fajar Muhammad Wicaksono, Hidayat. (2017). Mudah Belajar Mikrokontroler Arduino. Bandung: Informatika

Kadir, Abdul. (2015). Panduan Mempelajari Aneka Proyer Berbasis Mikrokontroler. Yogyakarta: Andi

Kadir, Abdul. (2015). From Zero to A Pro Arduino. Yogyakarta: Andi.

Kadir, Abdul. (2018). Arduino dan Sensor. Yogyakarta: Andi.

M. Iqbal Nur Fahmi, Wahyudi, Bambang Riyanta, (2012). Perancangan dan Pembuatan Alat Pelipat Baju Dengan Pengontrol Sistem Elektro Pneumatik dan PLC Untuk Industri Konveksi. Jurnal Material dan Proses Manufaktur. Vol..1 No. 2, 46-55.

Sutarbi, Tata. (2016). Sistem Informasi Manajemen. Yogyakarta: Andi.

Syahwil, Muhammad. (2013). Panduan Mudah Simulasi dan Praktik Mikrokontroler Arduino. Yogyakarta: Andi.

Taufiq Suyhadi Dwi Septian. (2010). Buku Pintar Robotika. Yogyakarta: Andi. 


\section{Appendix}
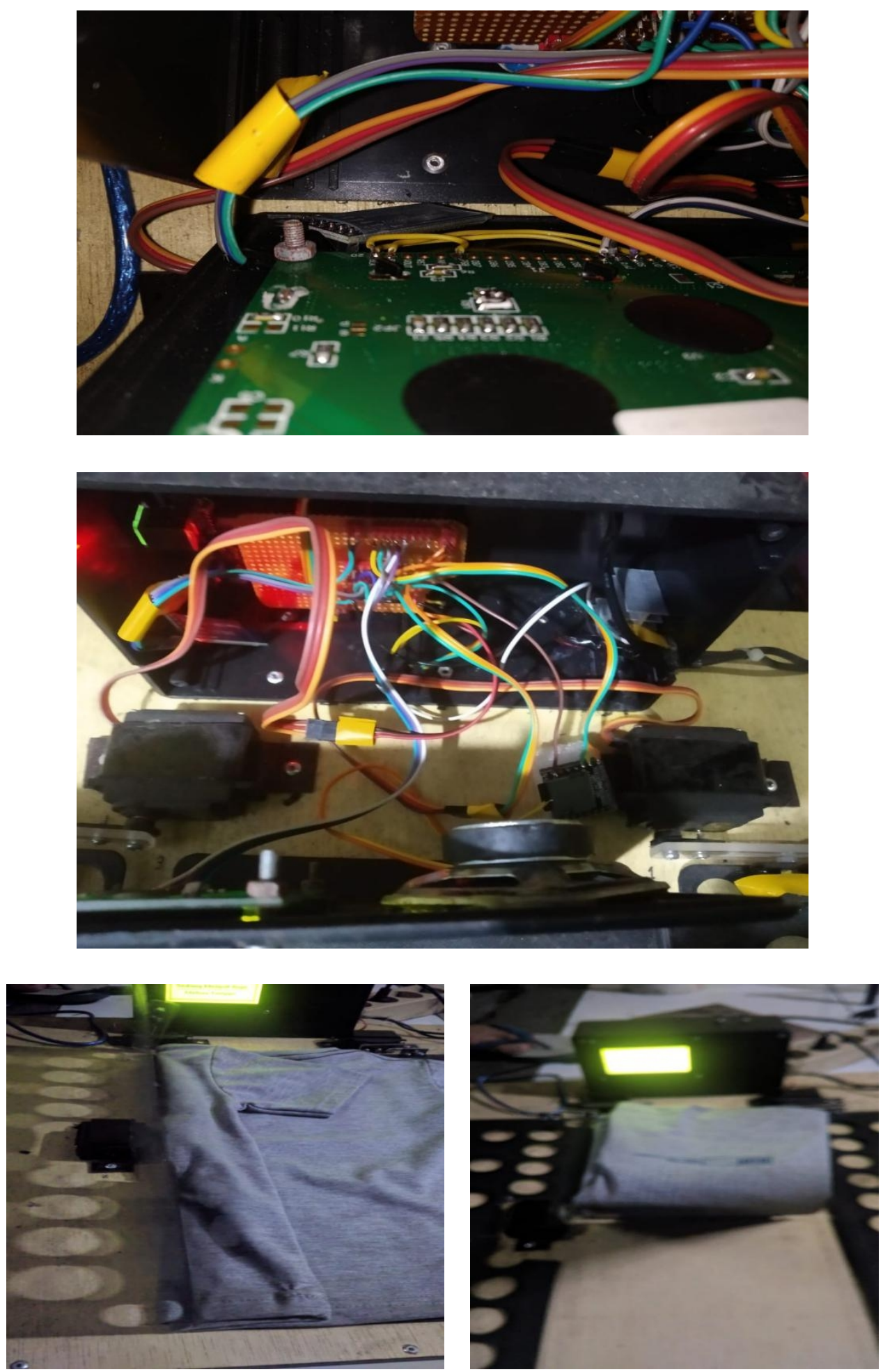

UNITEK. Vol.13 No.2 Juli - Desember 2020 p-ISSN 2089-3957 / e-ISSN 2580-2585 


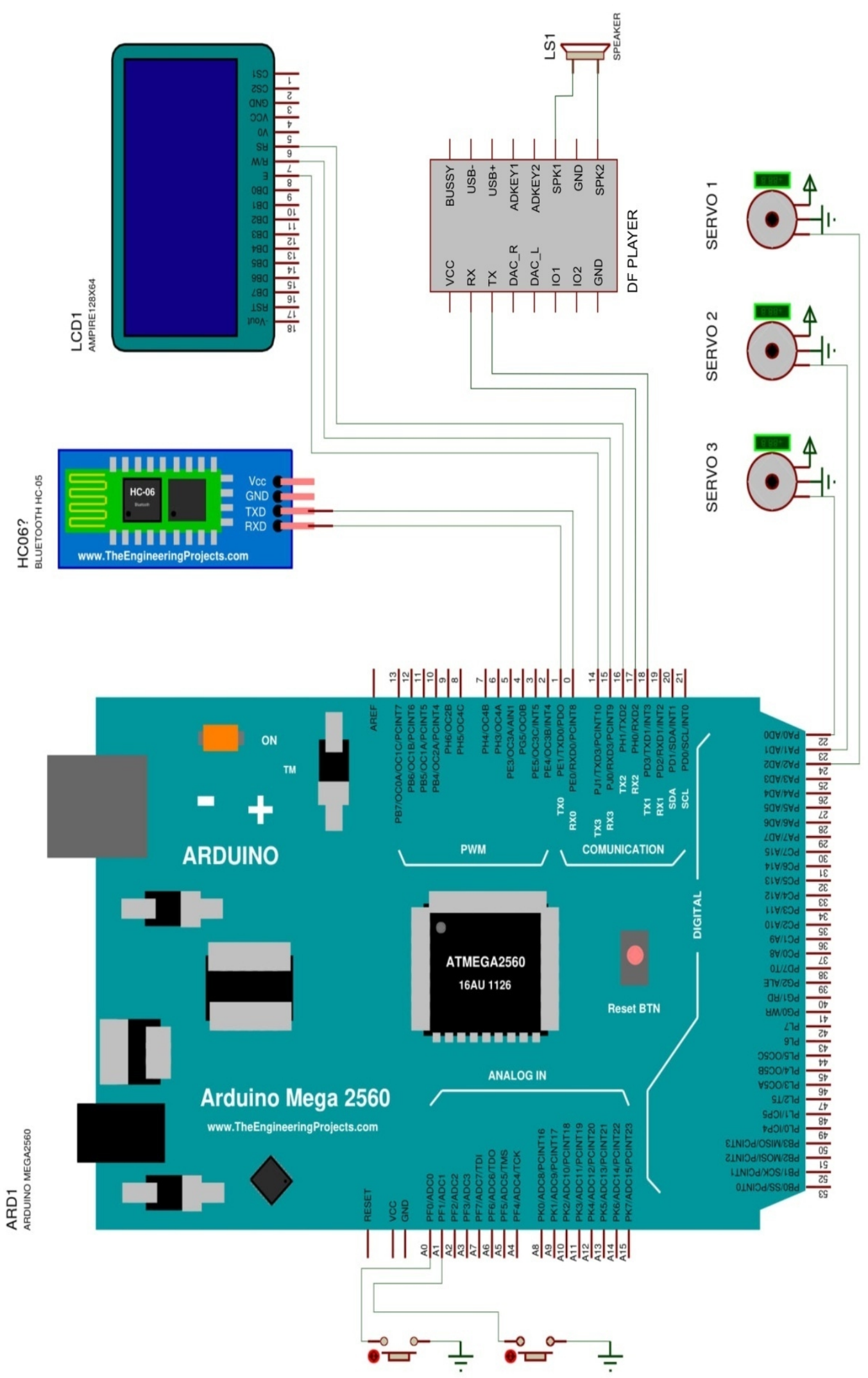

